\title{
Characterization by solid-phase microextraction-gas chromatography of the volatile profile of protected designation of origin Montasio cheese during ripening
}

\author{
N. Innocente, M. Munari, and M. Biasutti ${ }^{1}$ \\ Department of Food Science, University of Udine, Via Sondrio 2/A, 33100 Udine, Italy
}

\section{ABSTRACT}

Montasio is a typical protected designation of origin (PDO) Italian semi-hard and semi-cooked cheese produced in northeast Italy from raw or thermized cow's milk. The PDO label implies that the product has distinctive characteristics that are connected to traditional production methods. The aim of this work was to precisely characterize the volatile fraction of this Italian cheese. The volatile profile can be considered a fingerprint because the flavor of a cheese variety is the result of a specific balance between the volatile compounds produced during the ripening process. Analysis of the volatile profile of Montasio cheese was performed by solid-phase microextraction-gas chromatography. Six cheesemaking trials were performed, each in a different dairy located within the Montasio cheese production area. Cheeses were analyzed at 5 stages of ripening $(60,90,170,300$, and 365 d). Only 11 compounds were identified and measured: 5 fatty acids, 3 alcohols, 2 ketones, and 1 ester. The limited number of volatile compounds measured in the headspace of the Montasio cheese is probably due to the specific making process of this cheese, which affects evolution of the microflora and the biochemical processes of ripening. The total volatile fraction profile progressively increased from 60 to $170 \mathrm{~d}$, after which time it remained almost steady. The most important contributors were found to be ethanol, short-chain fatty acids $\left(\mathrm{C}_{2}\right.$ to $\left.\mathrm{C}_{6}\right)$, diacetyl, and ethyl hexanoate. Ethanol and short-chain fatty acids increased up to $170 \mathrm{~d}$, diacetyl increased up to $300 \mathrm{~d}$ and then declined, and ethyl hexanoate increased until the final stage.

Key words: Montasio cheese, volatile compound, solid-phase microextraction, ripening

Received May 3, 2012

Accepted September 7, 2012.

${ }^{1}$ Corresponding author: marialuisa.biasutti@uniud.it

\section{INTRODUCTION}

The volatile profile is generally recognized as one of the most important criteria for evaluating cheese quality. It reflects the odor and flavor of cheese and is recognized as being useful in characterizing the cheese and defining its ties to the area and methodology of production (Gioacchini et al., 2010). In fact, the volatile profile can be considered a fingerprint because the flavor of a cheese variety is the result of a specific balance between the volatile compounds produced during the ripening process (McSweeney and Sousa, 2000; Shakeel-ur-Rehman et al., 2000).

Cheese volatile compounds originate mainly from the breakdown of milk lactose, citrate, proteins, and lipids due to the activity of enzymes from coagulants, microorganisms (starter and nonstarter bacteria), and milk. Depending on cheese variety, microflora, and ripening conditions, lactose and citrate are metabolized by several different pathways to various compounds, with acetoin, diacetyl, acetate, acetaldehyde, and ethanol being the most common products. Lipolysis leads to the release of short- and intermediate-chain FA, which can be further metabolized or involved in esterification reactions to produce methyl ketones, secondary alcohols, lactones, and esters. Finally, proteolysis of caseins provides a range of small and intermediate-sized peptides and free AA. These are important precursors for a range of volatile compounds essential for flavor, such as amines, aldehydes, alcohols, acids, phenols, and sulfur compounds (Molimard and Spinnler, 1996; McSweeney and Sousa, 2000).

Several studies have been performed to characterize the volatile fraction of different hard and semi-hard cheeses, from the most common and well-known varieties, such as Emmental (Dirinck and De Winne, 1999), Gruyère (Mallia et al., 2005), Cheddar (Arora et al., 1995; Shakeel-ur-Rehman et al., 2000; Frank et al., 2004), Gouda (Dirinck and De Winne, 1999), Grana Padano (Moio and Addeo, 1998), and Parmigiano Reggiano (Barbieri et al., 1994; Careri et al., 1994; Bellesia et al., 2003), to cheese produced and consumed only at a local level, such as cheeses soaked in wine or fermented 
must (Innocente et al., 2007), Fossa cheese (Gioacchini et al., 2010), and Fontina Valle d'Aosta (Berard et al., 2007), among others.

The characterization and determination of the volatile components of cheese is now being increasingly carried out by headspace solid-phase microextraction (HS-SPME) coupled with GC (Frank et al., 2004; Mallia et al., 2005; Gioacchini et al., 2010) because of the method's reduced sample preparation time, high sensitivity, and limited risk of artifacts.

Montasio is a typical protected designation of origin (PDO) Italian semi-hard and semi-cooked cheese produced in northeast Italy from raw or thermized cow milk. The PDO denomination was obtained in 1996, according to the Council Regulation (EEC) No 2081/92 concerning the protection of geographical indications and designations of origin for agricultural products and foodstuffs. In total, 967,946 wheels of Montasio were produced in 2011. Montasio cheese is exported to Europe and worldwide, especially to the United States, Canada, Australia, and Arab countries; exports account for about $4 \%$ of total production.

Over the years, Montasio cheese has been extensively investigated in terms of its chemical composition (Innocente et al., 2002), ripening processes (Innocente, 1997; Innocente and Corradini, 1998; Innocente and D'Agostin, 2002), texture (Innocente et al., 2000, 2002), and sensory profile (Innocente, 2002). In addition, research has been conducted into the way different technological interventions, such as coating the surface of the cheese (Innocente, 1998) or lowering the warehouse temperature during the ripening period (Innocente and Corradini, 1996; Innocente and Biasutti, 2008), affect proteolysis and the quality characteristics of Montasio. Moreover, the characterization and dynamics of the lactic acid bacteria starters have been studied (Manzano et al., 1992; Citterio et al., 1995; Marino et al., 2003). Despite the number of studies, no data have previously been reported on the evolution of the volatile compounds of the Montasio cheese during ripening. Therefore, this study aimed to characterize the volatile fraction of Montasio cheese and to assess its evolution over the ripening period. The SPME method coupled with GC was used for this purpose.

\section{MATERIALS AND METHODS}

\section{Cheese Sampling}

Six cheesemaking trials were performed, with each trial being conducted in a different dairy located within the Montasio cheese production area. Milk processing was performed following the traditional production techniques laid down in the PDO Regulations for
Montasio cheese (EC Regulation No 1107/96). The unpasteurized milk was heated to 32 to $34^{\circ} \mathrm{C}$, inoculated with $1 \%$ of natural milk culture (a thermophilic culture obtained by incubating pasteurized milk at $44^{\circ} \mathrm{C}$ for 18 to $20 \mathrm{~h}$ ), and coagulated using calf rennet. The curd was cut into hazelnut-sized pieces and then cooked at 45 to $46^{\circ} \mathrm{C}$. After extraction from the vat, the curd was packed into 7 - to $8-\mathrm{kg}$ circular molds (diameter 30-35 $\mathrm{cm}$ and height $8 \mathrm{~cm}$ ). The mold was then placed in a pneumatic cheese press and pressed for $24 \mathrm{~h}$ at an average of $400 \mathrm{kPa}$. Then, the cheese was salted in brine (16-18\% wt/wt of sodium chloride) for $24 \mathrm{~h}$ at $11^{\circ} \mathrm{C}$. In each test, 30 cheeses produced from the same vat using the traditional process described above were ripened in the warehouse for $12 \mathrm{mo}$ at $8^{\circ} \mathrm{C}$ and $80 \%$ relative humidity. At 60, 90, 170, 300, and 365 d, samples were taken for analysis of volatile compounds.

\section{Volatile Compound Analysis}

Volatile compounds were determined by HS-SPME coupled with GC. Ten grams of sample was placed in a $50-\mathrm{mL}$ vial, which was crimped with a Teflon septum and an aluminum seal and then placed in a water bath at $60^{\circ} \mathrm{C}$ for $30 \mathrm{~min}$. A fiber assembly coated with divinylbenzene/carboxen/polydimethylsiloxane (DVB/ CAR/PDMS), 50 and $30 \mu \mathrm{m}$ film thickness, $2 \mathrm{~cm}$ long (Supelco, Bellefonte, PA) was exposed for $20 \mathrm{~min}$ in the headspace of the sample kept in the water bath at $60^{\circ} \mathrm{C}$ (Innocente et al., 2007). To optimize these SPME analytical conditions, the following parameters were tested: sample heating and extraction temperature $\left(40^{\circ} \mathrm{C}\right.$ and $\left.60^{\circ} \mathrm{C}\right)$, sample equilibration time $(20,30,40$, and 60 min), fiber coating (CAR/PDMS and DVB/CAR/ PDMS), and fiber exposure time (10, 20, 30, and 40 min). The DVB/CAR/PDMS fiber was found to be the most suitable in terms of sensitivity and repeatability, the extraction temperature of $60^{\circ} \mathrm{C}$ allowed the highest analytical response, the minimum equilibrium time was found to be $30 \mathrm{~min}$, and a 20-min fiber exposure time was chosen to avoid aroma competition phenomena.

Quantification of volatile compounds was performed using a Varian model 3400 gas chromatograph (Varian Inc., Walnut Creek, CA) equipped with a flame-ionization detector (set at $250^{\circ} \mathrm{C}$ ). Volatile compounds were thermally desorbed from the SPME fiber in the injector port (set up at $250^{\circ} \mathrm{C}$ ) in splitless mode, and the split valve was opened 3 min after injection. A 3-min desorption time was adopted because preliminary tests proved that this time allowed complete desorption of analytes from the fiber. Helium was the carrier gas with a flow rate of $1 \mathrm{~mL} / \mathrm{min}$. Separation was performed on an Econo-Cap Ec-Wax column (30-m long, 0.25-mm inner diameter, 0.25- $\mu \mathrm{m}$ film thickness; Alltech, State 
College, PA). The oven temperature was held at $50^{\circ} \mathrm{C}$ for $5 \mathrm{~min}$, and then increased to $230^{\circ} \mathrm{C}\left(10^{\circ} \mathrm{C} / \mathrm{min}\right.$, held $10 \mathrm{~min})$ to a final temperature of $250^{\circ} \mathrm{C}\left(10^{\circ} \mathrm{C} / \mathrm{min}\right.$, held 10 min; Innocente et al., 2007). The absolute peak area of each compound was used for comparing and interpreting the data.

Identification of volatile compounds was achieved using GC-MS. The chromatographic conditions and the column used were the same as those used in the GCflame-ionization detector analysis. The GC-MS system consisted of a model 3400 Varian gas chromatograph coupled to a model ion trap detector Varian Saturn mass spectrometer. The ion trap detector MS conditions were as follows: the temperatures of the manifold and the transfer line were $170^{\circ} \mathrm{C}$ and $250^{\circ} \mathrm{C}$, respectively; electron impact mass spectra were recorded at $70 \mathrm{eV}$; the ionization current was $10 \mu \mathrm{A}$; and the scan rate was 1.5 scans/s. Compounds were identified by comparing their mass spectra with those of a mass spectrum library (Wiley Library, 5th ed. Scientific Instrument Services Inc., Ringoes, NJ). Moreover, Kovats' retention indices were determined and compared with the retention indices of the compounds available in the literature. Identification was checked by using commercial reference compounds provided by SigmaAldrich (St. Louis, MO).

\section{Statistical Analysis}

Six cheesemaking batches were studied. At each sampling time, 2 cheeses were taken and analyzed for the volatile compounds. The analysis was carried out twice, thus the data shown are the averages of the 24 values obtained. One-way ANOVA and Tukey's test for multiple comparisons were used, and the differences between the means were considered statistically significant for $P$-values $\leq 0.05$. All statistical analyses were conducted using Statistical Discovery JMP 3.0 for Windows (SAS Institute Inc., Cary, NC).

\section{RESULTS AND DISCUSSION}

The volatile profile of Montasio cheese was evaluated on cheese samples from 60 to $365 \mathrm{~d}$ of ripening, which correspond to the minimum ripening time required by the PDO label and the longest ripening period normally adopted.

Overall, in the headspace of the Montasio cheese samples, 11 compounds were identified ( $5 \mathrm{FA}, 3$ alcohols, 2 ketones, and 1 ester; Table 1). A larger number of volatile compounds has been reported for other hard and semi-hard cheeses, such as Grana Padano (Moio and Addeo, 1998), Parmigiano Reggiano (Barbieri et al., 1994; Careri et al., 1994; Bellesia et al., 2003),
Cheddar (Arora et al., 1995; Shakeel-ur-Rehman et al., 2000; Frank et al., 2004), Gouda (Dirinck and De Winne, 1999), and Fontina (Berard et al., 2007). It is believed that the smaller number of volatile compounds measured in the headspace of Montasio cheese is probably due to the specific making process of this cheese that, in turn, affects the evolution of the microflora and the biochemical processes of ripening. On the other hand, the quantity of volatile compounds detected was consistent with the profile of 60-d-old Montasio cheese samples reported by Polentarutti et al. (2001). Those authors, in fact, identified 6 short-chain FA, 2 primary alcohols, and 3 methyl-ketones.

Figure 1 shows the evolution of the total volatile fraction profile, expressed as an average value of the sum of the absolute areas of the peaks measured in the headspace of the Montasio cheese samples during ripening. The total volatile profile of the cheeses progressively increased from 60 to $170 \mathrm{~d}$, after which time it remained almost steady. However, changes in the profile of single volatile compounds or in the ratio between the various chemical classes over the ripening period were expected because cheese is a biochemically dynamic product that undergoes significant changes over time. Three major biochemical processes occur during cheese ripening: lactose fermentation, proteolysis, and lipolysis, leading to the degradation of the residual lactose, lactate, citrate, casein, and the fat of the curd, and the formation of cheese aroma compounds. The molecules derived from these metabolic pathways are FFA, ketones, aldehydes, alcohols, esters, lactones, terpenes, phenolic and sulfur compounds, furans, amines, and pyrazines (Molimard and Spinnler, 1996; McSweeney and Sousa, 2000; Curioni and Bosset, 2002).

Table 2 shows the mean values of the sum of the absolute peak areas of the volatile compounds, grouped according to chemical class (alcohols, ketones, FA, and esters). Alcohols and FFA were the most significant contributors to the volatile profile of the cheeses. As expected, significant changes in the volatile profile occurred over the ripening period: alcohols and FA increased until $170 \mathrm{~d}$ and then remained almost steady; ketones increased up to $300 \mathrm{~d}$ and esters progressively increased until the end of the ripening period. These behaviors were derived from those of the single volatile compounds.

Specifically, in regard to the alcohol class, ethanol, 2,3-butanediol, and 3-methyl-1-butanol were detected in the headspace of the Montasio samples (Figure 2). Fermentation of lactose and proteolysis are the main biochemical pathways occurring in Montasio cheese over the ripening period (Innocente and Corradini, 1996; Innocente and Corradini, 1998; Innocente and D'Agostin, 2002). Therefore, both lactose fermentation and amino 
Table 1. Volatile compounds identified by solid-phase microextraction GC-MS analysis in the headspace of Montasio cheese samples

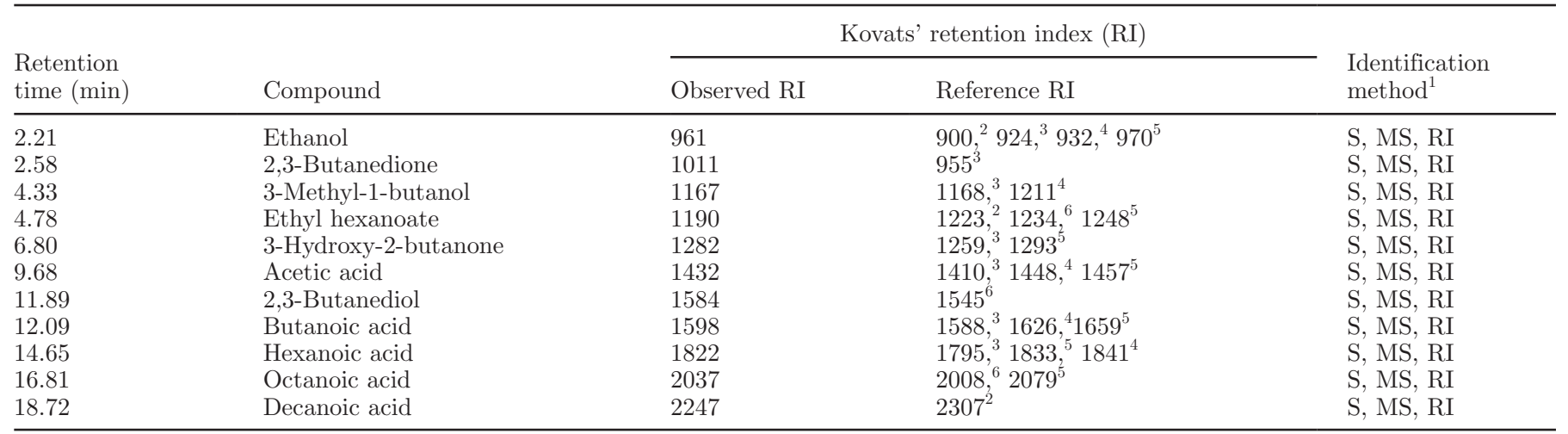

${ }^{1} \mathrm{~S}=$ comparison of mass spectra and retention time with those of standard compounds; $\mathrm{MS}=$ comparison of mass spectra with those reported in a mass spectrum library (Wiley Library, 5th ed. Scientific Instrument Services Inc., Ringoes, NJ); RI = comparison of elution order according to different references (footnotes 2 through 6 ).

${ }^{2}$ Jennings and Shimaboto (1980).

${ }^{3}$ Lecanu et al. (2002).

${ }^{4}$ Vichi et al. (2003).

${ }^{5}$ Biasutti and Innocente (2006).

${ }^{6}$ Baek and Cadwallader (1999).

acid degradation could explain the formation of these alcohols in Montasio cheese.

Ethanol was found to be the most abundant compound in all Montasio samples (Figure 2A). It increased up to $170 \mathrm{~d}$ and thereafter remained almost steady. 2,3-Butanediol and 3-methyl-1-butanol (Figure 2B) were comparable and present at a lower level (taking into account the peak area). They both showed a decrease as ripening time progressed.

The alcohols identified in the Montasio samples have been reported in various cheeses. Ethanol was the most abundant alcohol in Cheddar (Arora et al., 1995) and Reggianito Argentino (Wolf et al., 2010). It has also been detected in large quantities in Fontina (Berard et al., 2007), whereas a low percentage is reported in Parmigiano Reggiano (Barbieri et al., 1994). 3-Methyl1-butanol was identified in large quantities in Grana Padano (Moio and Addeo, 1998) and Fontina (Berard et al., 2007) and as a minor odorant in Parmigiano Reggiano (Barbieri et al., 1994; Bellesia et al., 2003), Reggianito Argentino (Wolf et al., 2010), and Cheddar
(Shakeel-ur-Rehman et al., 2000). 3-Methyl-1-butanol is reported to confer alcoholic and floral notes (Molimard and Spinnler, 1996; Moio and Addeo, 1998). 2,3-Butanediol has been identified in Reggianito Argentino (Wolf et al., 2010) and Parmigiano Reggiano (Barbieri et al., 1994; Careri et al., 1994; Bellesia et al., 2003). No odor descriptors have been reported in the literature for this compound.

3-Hydroxy-2-butanone and 2,3-butanedione were the ketones identified and measured in the headspace of Montasio cheese samples during the ripening period (Figure 3). These compounds derive from lactose or residual citrate catabolism and arise mainly from the activity of lactic acid bacteria (Molimard and Spinnler, 1996; McSweeney and Sousa, 2000). In the Montasio cheese samples, 3-hydroxy-2-butanone was present at a constant level, whereas 2,3-butanedione increased progressively up to $300 \mathrm{~d}$ (Figure 3). These $2 \mathrm{com}$ pounds are known to confer buttery notes to cheese (Molimard and Spinnler, 1996; Moio and Addeo, 1998; Curioni and Bosset, 2002; Frank et al., 2004; Mallia

Table 2. Mean values and standard deviations of the sum of the absolute peak areas (arbitrary units) of the volatile compounds, grouped according to chemical class, measured in Montasio cheese samples during ripening

\begin{tabular}{lcccc}
\hline $\begin{array}{l}\text { Ripening } \\
\text { time (d) }\end{array}$ & Alcohols & Ketones & Fatty acids & Esters \\
\hline 60 & $7,716^{\mathrm{c}} \pm 396$ & $415^{\mathrm{d}} \pm 76$ & $4,827^{\mathrm{c}} \pm 467$ & $57^{\mathrm{e}} \pm 3$ \\
90 & $9,087^{\mathrm{b}} \pm 489$ & $571^{\mathrm{c}} \pm 64$ & $6,255^{\mathrm{b}} \pm 762$ & $133^{\mathrm{d}} \pm 37$ \\
170 & $12,297^{\mathrm{a}} \pm 1,874$ & $795^{\mathrm{b}} \pm 105$ & $10,727^{\mathrm{a}} \pm 1506$ & $765^{\mathrm{c}} \pm 115$ \\
300 & $11,074^{\mathrm{a}} \pm 1,006$ & $1,616^{\mathrm{a}} \pm 88$ & $10,919^{\mathrm{a}} \pm 632$ & $1,132^{\mathrm{b}} \pm 200$ \\
365 & $12,625^{\mathrm{a}} \pm 1,274$ & $1,406^{\mathrm{a}} \pm 153$ & $11,287^{\mathrm{a}} \pm 1241$ & $1,970^{\mathrm{a}} \pm 362$ \\
\hline
\end{tabular}

${ }^{a-e}$ Different letters in the same column indicate significant statistical differences (Tukey's test, $P \leq 0.05$ ). 


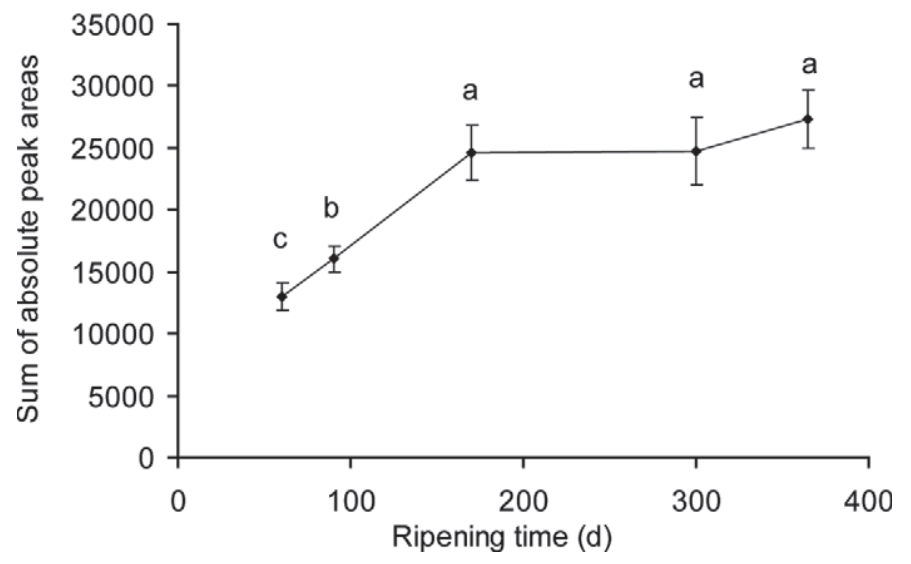

Figure 1. Total volatile profile expressed as the mean value of the sum of the absolute areas measured in the headspace of Montasio cheese samples during ripening. Mean values with different letters differ statistically at $P \leq 0.05$ according to Tukey's test.

et al., 2005). 3-Hydroxy-2-butanone was identified in the volatile fraction of Cheddar (Arora et al., 1995; Shakeel-ur-Rehman et al., 2000; Curioni and Bosset, 2002), Emmental, and Gouda (Dirinck and De Winne, 1999), as well as in the hard cheeses for grating, namely Parmigiano Reggiano (Barbieri et al., 1994), Grana Padano (Moio and Addeo, 1998), Trentingrana (Endrizzi et al., 2012), and Reggianito Argentino (Wolf et al., 2010). 2,3-Butanedione was found to be a key odor compound of Gruyère (Mallia et al., 2005) and is also present in Parmigiano Reggiano (Barbieri et al., 1994), Reggianito Argentino (Wolf et al., 2010), Fontina (Berard et al., 2007), Cheddar (Arora et al., 1995; Curioni and Bosset, 2002; Frank et al., 2004), and Emmental (Curioni and Bosset, 2002).

Free fatty acids form mainly from lipolysis, proteolysis, and lactose fermentation during cheese ripening (Barbieri et al., 1994; Curioni and Bosset, 2002). Most of the FA having between 4 and 20 carbon atoms come from the lipolysis of triglycerides; a lower proportion of FFA, which generally have between 2 and 6 carbon atoms, originate from the degradation of lactose and amino acids; the shorter FA can also be derived from ketones, esters, and aldehydes by oxidation (Curioni and Bosset, 2002).

The volatile profile of the Montasio cheese samples was characterized by short-chain and medium-chain, even-numbered FA $\left(\mathrm{C}_{2}\right.$ to $\mathrm{C}_{10}$; Figure 4$)$. Acetic acid showed an increasing trend until the later ripening stages, butanoic and hexanoic acids increased until 170 $\mathrm{d}$, and thereafter remained almost steady, whereas no significant changes in the absolute peak area of octanoic and decanoic acids were measured over the ripening period. Previous studies (Citterio et al., 1995; Manzano et al., 1992; Marino et al., 2003) demonstrated that the
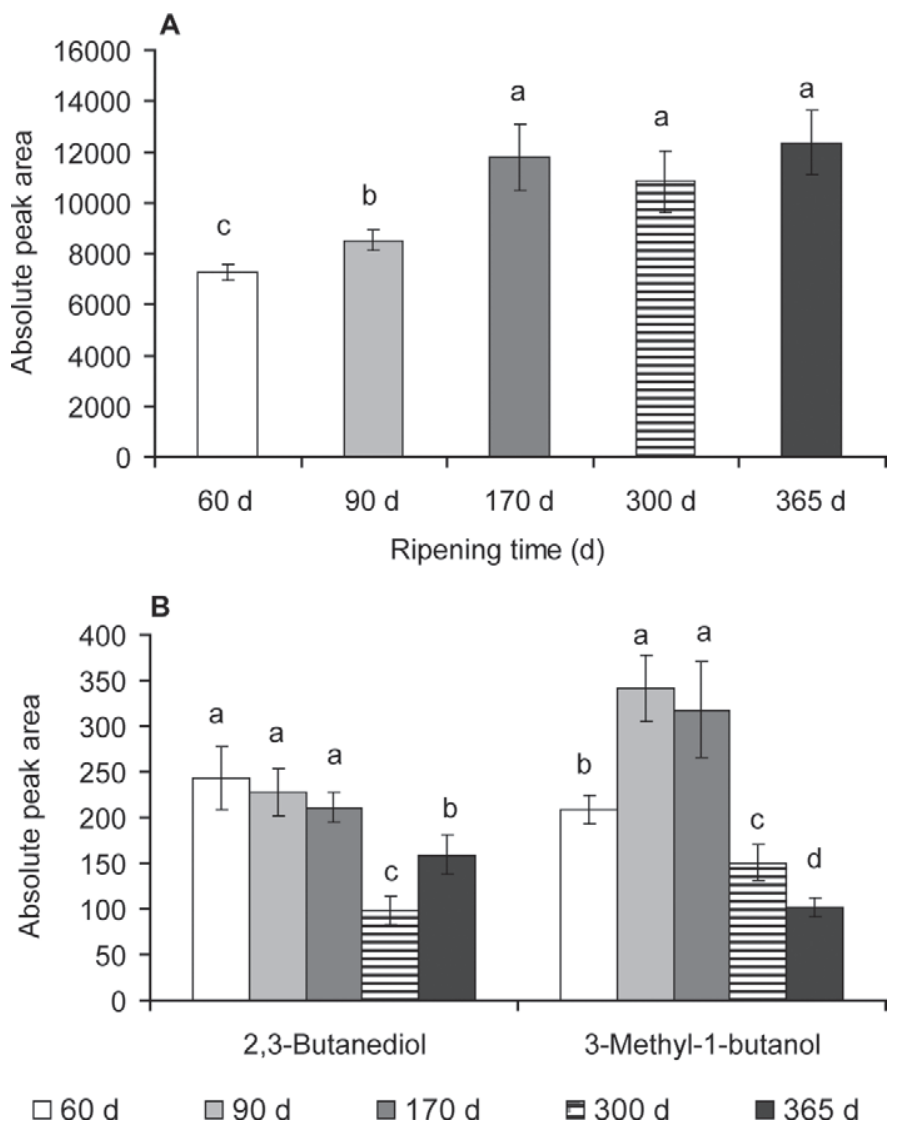

Figure 2. Profiles of (A) ethanol and (B) primary alcohols expressed as the mean value of the absolute peak area measured in the headspace of Montasio cheese samples during ripening. For each compound, mean values with different letters differ statistically at $P$ $\leq 0.05$ according to Tukey's test.

Montasio cheese starter is characterized mainly by homofermentative lactic acid bacteria (thermophilic and mesophilic), but limited amounts of heterofermentative lactic acid bacteria are also acceptable $(\leq 11 \%)$, as they are responsible for the characteristic holes in Montasio cheese (Innocente and Corradini, 1998; Innocente et al., 2002). Moreover, even though fermentation of lactose and proteolysis are the main biochemical pathways occurring in Montasio cheese ripening (Innocente and Corradini, 1996; Innocente and Corradini, 1998; Innocente and D'Agostin, 2002), lipolytic species in the microbial composition of Montasio starter have also been reported (Polentarutti et al., 2001; Marino et al., 2003).

Because of their low perception thresholds, short and medium-chain, even-numbered $\mathrm{FA}\left(\mathrm{C}_{4}\right.$ to $\left.\mathrm{C}_{12}\right)$ play an important role in the flavor profile of a wide variety of cheeses (Molimard and Spinnler, 1996; Curioni and Bosset, 2002). Acetic acid has a typical vinegary odor, sour and sharp (Curioni and Bosset, 2002; Frank et al., 2004), and is reported to be a key odorant of aged Cheddar, Gruyère, and Emmental (Shakeel-ur-Rehman 


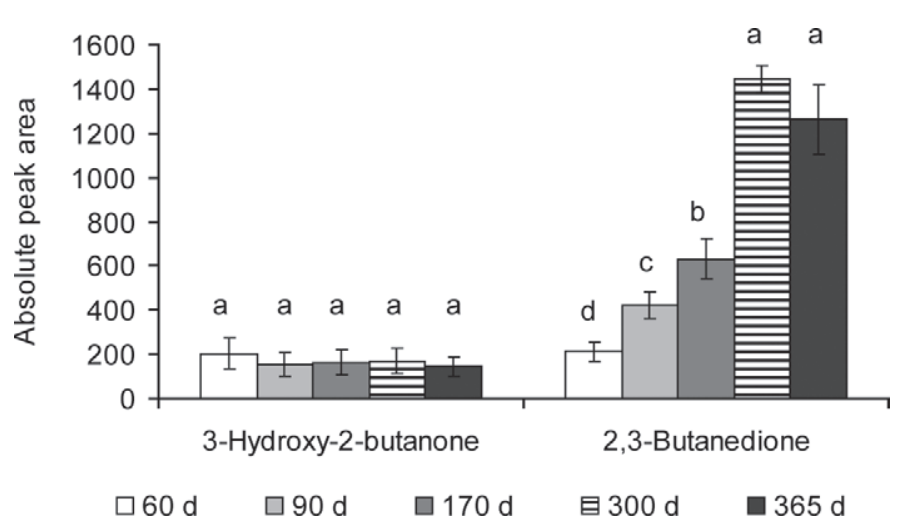

Figure 3. Profiles of ketones expressed as the mean value of the absolute peak area measured in the headspace of Montasio cheese samples during ripening. For each compound, mean values with different letters differ statistically at $P \leq 0.05$ according to Tukey's test.

et al., 2000; Curioni and Bosset, 2002; Mallia et al., 2005) as well as the hard cheeses for grating (Barbieri et al., 1994; Moio and Addeo, 1998; Bellesia et al., 2003; Wolf et al., 2010; Endrizzi et al., 2012). Butanoic acid has a rancid cheese-like odor (Curioni and Bosset, 2002; Frank et al., 2004) and was found to significantly contribute to the aroma of various cheeses, such as the hard cheeses for grating (Barbieri et al., 1994; Moio and Addeo, 1998; Bellesia et al., 2003; Wolf et al., 2010; Endrizzi et al., 2012), aged Cheddar (Shakeel-ur-Rehman et al., 2000), Gouda and Emmental (Dirinck and De Winne, 1999), and Gruyère (Mallia et al., 2005). Hexanoic acid is perceived as a goat-like or animal-like odor (Curioni and Bosset, 2002; Frank et al., 2004; Mallia et al., 2005) and is an important flavor component of hard cheeses for grating (Barbieri et al., 1994; Moio and Addeo, 1998; Bellesia et al., 2003; Wolf et al., 2010; Endrizzi et al., 2012), Gruyère (Mallia et al., 2005), Emmental and Gouda (Dirinck and De Winne, 1999),

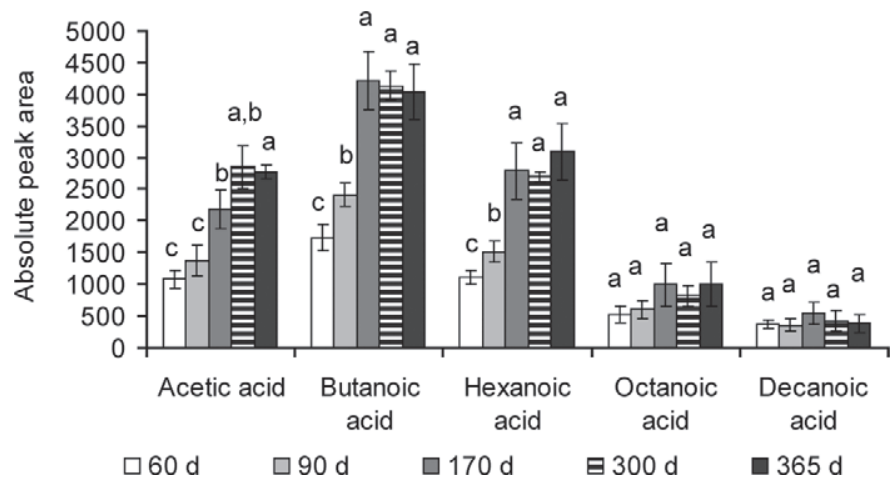

Figure 4. Profiles of the fatty acids expressed as the mean value of the absolute peak area measured in the headspace of Montasio cheese samples during ripening. For each compound, mean values with different letters differ statistically at $P \leq 0.05$ according to Tukey's test.

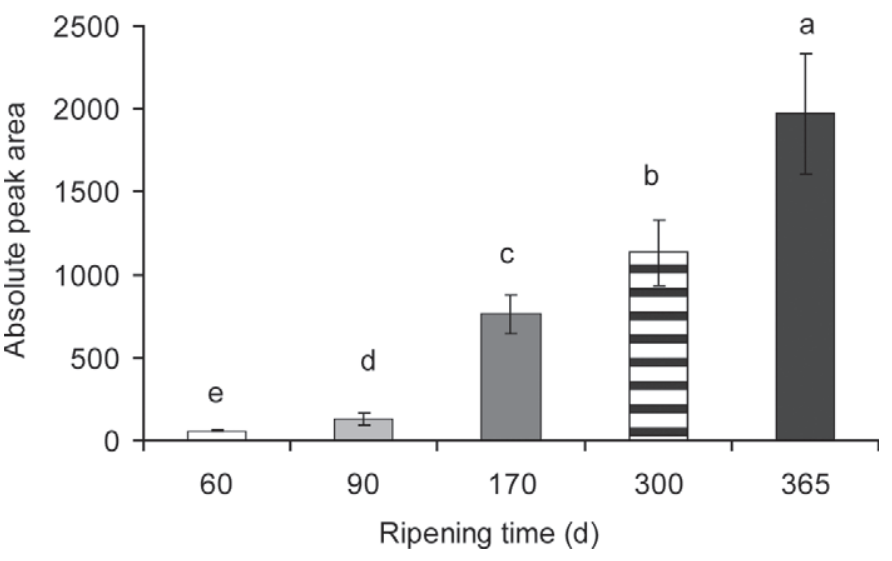

Figure 5. Profile of ethyl hexanoate expressed as the mean value of the absolute peak area measured in the headspace of Montasio cheese samples during ripening. Mean values with different letters differ statistically at $P \leq 0.05$ according to Tukey's test.

and Cheddar (Curioni and Bosset, 2002; Shakeel-urRehman et al., 2000). Octanoic and decanoic acids are listed among the odorants of different cheeses, such as the hard cheeses for grating (Barbieri et al., 1994; Moio and Addeo, 1998; Bellesia et al., 2003; Wolf et al., 2010; Endrizzi et al., 2012), Emmental and Gouda (Dirinck and De Winne, 1999), Cheddar (Shakeel-ur-Rehman et al., 2000), and Fossa cheese (Gioacchini et al., 2010).

Ethyl hexanoate was the most significant ester compound determined in the headspace of Montasio samples over the ripening period (Figure 5). It progressively increased during cheese ripening, probably because of an esterification reaction between ethanol and hexanoic acid. Ethyl butanoate, ethyl octanoate, and ethyl decanoate were also detected in the volatile profile of the cheese samples. However, they were not considered significant because their absolute flameionization detection area was close to the baseline signal of the chromatographic profile, similar to that described for isoamyl acetate. Ethyl hexanoate is reported to have fruity notes (Molimard and Spinnler, 1996; Curioni and Bosset, 2002; Frank et al., 2004) and is an important component of the volatile fraction of several cheeses, such as Fontina (Berard et al., 2007), aged Cheddar (Shakeel-ur-Rehman et al., 2000), Grana Padano (Moio and Addeo, 1998; Frank et al., 2004), Trentingrana (Endrizzi et al., 2012), and Parmigiano Reggiano (Barbieri et al., 1994; Bellesia et al., 2003).

\section{CONCLUSIONS}

The volatile fraction of Montasio, a PDO semi-hard Italian cheese, was characterized and analyzed during its ripening period. In the headspace of Montasio cheese, FA, alcohols, ketones, and ester compounds 
were identified and determined. Significant changes in the volatile profile occurred over the ripening period: alcohols and FA increased until $170 \mathrm{~d}$ and remained almost steady thereafter; ketones increased up to $300 \mathrm{~d}$, and esters progressively increased until the end of the ripening period. These behaviors were related to that of the single volatile compounds. This study contributes to the characterization of Montasio cheese by providing a description and evolution of the volatile profile. The information could be useful in preserving this cheese in the market and provides an additional means to evaluate the effects of new technological interventions or changes in the traditional production techniques described in the PDO regulations for this cheese.

\section{REFERENCES}

Arora, G., F. Cormier, and B. Lee. 1995. Analysis of odor-active volatiles in Cheddar cheese headspace by multidimensional GC/MS/ sniffing. J. Agric. Food Chem. 43:748-752.

Baek, H. H., and K. R. Cadwallader. 1999. Contribution of free and glycosidically bound volatile compounds to the aroma of muscadine grape juice. J. Food Sci. 64:441-444.

Barbieri, G., L. Bolzoni, M. Careri, A. Mangia, G. Parolari, S. Spagnoli, and R. Virgili. 1994. Study of the volatile fraction of Parmesan cheese. J. Agric. Food Chem. 42:1170-1176.

Bellesia, F., A. Pinetti, U. M. Pagnoni, R. Rinaldi, C. Zucchi, L. Caglioti, and G. Palyi. 2003. Volatile components of Grana Parmigiano-Reggiano type hard cheese. Food Chem. 83:55-61.

Berard, J., F. Bianchi, M. Careri, A. Chatel, A. Mangia, and M. Musci. 2007. Characterization of the volatile fraction and of free fatty acids of "Fontina Valle d'Aosta", a protected designation of origin Italian cheese. Food Chem. 105:293-300.

Biasutti, M., and N. Innocente. 2006. Effect of a post-processing phase on the volatile flavour compounds of Asìno cheese. Ital. J. Food Sci. 2:163-176.

Careri, M., P. Manini, S. Spagnoli, G. Barbieri, and L. Bolzoni. 1994. Simultaneous distillation-extraction and dynamic headspace methods in the gas chromatographic analysis of Parmesan cheese volatiles. Chromatographia 38:386-394.

Citterio, B., M. Manzano, M. Maifreni, and G. Rondinini. 1995. Some microbiological aspects of the Montasio cheese production. Sci. Tecn. Latt. Cas. 46:7-19.

Curioni, P. M. G., and J. O. Bosset. 2002. Key odorants in various cheese types as determined by gas chromatography-olfactometry. Int. Dairy J. 12:959-984.

Dirinck, P., and A. De Winne. 1999. Flavour characterization and classification of cheeses by gas chromatographic-mass spectrometric profiling. J. Chromatogr. A 847:203-208.

Endrizzi, I., A. Fabris, F. Biasioli, E. Aprea, E. Franciosi, E. Poznanski, A. Cavazza, and F. Gasperi. 2012. The effect of milk collection and storage conditions on the final quality of Trentingrana cheese: Sensory and instrumental evaluation. Int. Dairy J. 23:105-114.

Frank, D. C., C. M. Owen, and J. Patterson. 2004. Solid phase microextraction (SPME) combined with gas-chromatography and olfactometry-mass spectrometry for characterization of cheese aroma compounds. Lebenson. Wiss. Technol. 37:139-154.

Gioacchini, A. M., M. De Santi, M. Guescini, G. Brandi, and V. Stocchi. 2010. Characterization of the volatile organic compounds of Italian 'Fossa' cheese by solid-phase microextraction gas chromatography/mass spectrometry. Rapid Commun. Mass Spectrom. 24:3405-3412.

Innocente, N. 1997. Free amino acids and water-soluble nitrogen as ripening indices in Montasio cheese. Lait 77:359-369.
Innocente, N. 1998. The application of a plastic covering to cheese at the beginning of maturation: Preliminary studies. Sci. Tecn. Latt. Cas. 49:214-222.

Innocente, N. 2002. Sensorial profiles of Montasio cheese at different levels of ripening. Sci. Tecn. Latt. Cas. 53:173-187.

Innocente, N., and M. Biasutti. 2008. Effect of ripening temperature on maturation trend, flavour profile and sensorial characteristics of Montasio cheese. Sci. Tecn. Latt. Cas. 59:55-70.

Innocente, N., M. Biasutti, and P. Comuzzo. 2007. Characterization of a traditional semi-hard Italian cheese produced by soaking in wine. Food Chem. 105:1452-1456.

Innocente, N., and C. Corradini. 1996. Effect of ripening temperature on the maturation of Montasio cheese. Ital. J. Food Sci. 4:291-302.

Innocente, N., and C. Corradini. 1998. Gamma-aminobutyric acid as an indicator of fermentative processes responsible for the formation of holes typical in Montasio cheese. Milchwissenschaft 53:202-206.

Innocente, N., and P. D'Agostin. 2002. Formation of biogenic amines in a typical semihard Italian cheese. J. Food Prot. 65:1498-1501.

Innocente, N., P. Pittia, O. Stefanuto, and C. Corradini. 2000. Texture profile of Montasio cheese. Milchwissenschaft 55:507-510.

Innocente, N., P. Pittia, O. Stefanuto, and C. Corradini. 2002. Correlation among instrumental texture, chemical composition and presence of characteristics holes in a semi-hard Italian cheese. Milchwissenschaft 57:204-208.

Jennings, W., and T. Shimaboto. 1980. Qualitative Analysis of Flavor and Fragrance Volatiles by Glass Capillary Gas Chromatography. Academic Press, New York, NY.

Lecanu, L., V. Ducruet, C. Jouquand, J. J. Gratadoux, and A. Feigenbaum. 2002. Optimization of headspace solid-phase microextraction (SPME) for the odor analysis of surface-ripened cheese. J. Agric. Food Chem. 50:3810-3817.

Mallia, S., E. Fernández-García, and J. O. Bosset. 2005. Comparison of purge and trap and solid phase microextraction techniques for studying the volatile aroma compounds of three European PDO hard cheeses. Int. Dairy J. 15:741-758.

Manzano, M., B. Citterio, G. Rondinini, and M. de Bertoldi. 1992. Microbiological aspects of natural starter in Montasio cheesemaking. Ann. Microbiol. 42:163-170.

Marino, M., M. Maifreni, and G. Rondinini. 2003. Microbiological characterization of artisanal Montasio cheese: Analysis of its indigenous lactic acid bacteria. FEMS Microbiol. Lett. 229:133-140.

McSweeney, P. L. H., and M. J. Sousa. 2000. Biochemical pathways for the production of flavour compounds in cheeses during ripening: A review. Lait 80:293-324.

Moio, L., and F. Addeo. 1998. Grana Padano cheese aroma. J. Dairy Res. 65:317-333.

Molimard, P., and H. E. Spinnler. 1996. Review: Compounds involved in the flavor of surface mold-ripened cheeses: Origins and properties. J. Dairy Sci. 79:169-184.

Polentarutti, M., L. Piasenzotto, G. Comi, L. Conte, and A. Surmely. 2001. Influence of season on raw milk and on Montasio cheese aroma. Ind. Aliment. 40:1331-1342.

Shakeel-ur-Rehman, J. M. Banks, E. Y. Brechany, D. D. Muir, P. L. H. McSweeney, and P. F. Fox. 2000. Influence of ripening temperature on the volatile profile and flavour of Cheddar cheese made from raw or pasteurised milk. Int. Dairy J. 10:55-65.

Vichi, S., A. I. Castellote, L. Pizzale, L. S. Conte, S. Buxaderas, and E. López-Tamames. 2003. Analysis of virgin oil volatile compounds by headspace solid-phase microextraction coupled to gas chromatography with mass spectrometric and flame ionization detection. J. Chromatogr. A 983:19-33.

Wolf, I. V., M. C. Perotti, S. M. Bernal, and C. A. Zalazar. 2010. Study of the chemical composition, proteolysis, lipolysis and volatile compounds profile of commercial Reggianito Argentino cheese: Characterization of Reggianito Argentino cheese. Food Res. Int. 43:1204-1211. 